\title{
Attention Deficit Hyperactivity Disorder And Borderline Personality Disorder In Adults: A Review Of Their Links And Risks
}

This article was published in the following Dove Press journal:

Neuropsychiatric Disease and Treatment

\author{
Luisa Weiner ${ }^{1,2}$ \\ Nader Perroud ${ }^{3,4}$ \\ Sébastien Weibel (1D) 1,5 \\ 'Department of Psychiatry, University \\ Hospital of Strasbourg, Strasbourg, \\ France; '2Laboratoire De Psychologie Des \\ Cognitions, University of Strasbourg, \\ Strasbourg, France; ${ }^{3}$ Department of \\ Psychiatry, University Hospitals of \\ Geneva, Geneva, Switzerland; \\ ${ }^{4}$ Department of Psychiatry, Dalhousie \\ University, Halifax, Nova Scotia, Canada; \\ ${ }^{5}$ Inserm UIII4, Strasbourg, France
}

Correspondence: Sébastien Weibel Department of Psychiatry, University Hospital of Strasbourg, I Place De L'hôpital, Strasbourg 67000, France

Tel +33388115157

Email sebastien.weibel@chru-strasbourg.fr

\begin{abstract}
Attention deficit hyperactivity disorder (ADHD) and borderline personality disorder (BPD) are particularly common disorders, that are highly comorbid in adult populations. The symptomatic overlap between adult ADHD and BPD includes impulsivity, emotional dysregulation and interpersonal impairment, which makes the differential diagnosis difficult. Our review aims at focusing on recent data on the comorbid ADHD+BPD form, as well as the risk factors involved in the emergence of the two disorders. While adult ADHD and BPD share some genetic and temperamental risk factors, adult ADHD is characterized by more severe trait-impulsivity compared to non-comorbid BPD; BPD patients display more severe trait-emotion regulation symptoms compared to non-comorbid ADHD. Patients with the comorbid ADHD+BPD form have severe symptoms in both dimensions. Early-life exposure to adverse events is a shared risk factor for the development of ADHD and BPD, but type and timing of adversity seem to play a differential role in the development of BPD and ADHD symptoms. Age of onset used to be a discriminative diagnostic criterion between ADHD, an early-onset neurodevelopmental disorder, and $\mathrm{BPD}$, a late-onset psychological disorder. However, this distinction has been recently called into question, increasing the need for more research aiming at delineating the disorders from a developmental and clinical standpoint. Clinicians should carefully consider the comorbidity, and consider ADHD and BPD dimensionally, in order to provide more effective patient management. This might improve early preventive interventions, and treatment for comorbid conditions in adulthood.
\end{abstract}

Keywords: ADHD, borderline personality disorder, adults, emotion regulation, impulsivity

\section{Introduction}

Attention deficit/hyperactivity disorder (ADHD) is commonly conceptualized as a neurodevelopmental disorder characterized by three clusters of symptoms - i.e., inattention, hyperactivity and impulsivity -, starting before the age of twelve according to the DSM- $5^{1}$ At least $50 \%$ of the children with ADHD still meet criteria for ADHD diagnosis in adulthood, and estimates of prevalence of ADHD in adulthood range from $4 \%$ to $5 \%^{2}$ Symptomatic expressions in adults differ, however, ${ }^{3,4}$ as adults may display fewer symptoms and more internalized rather than externalized forms of hyperactivity ${ }^{1}$ Although not included among the core diagnostic criteria of ADHD in the DSM- $5^{1}$ emotion dysregulation is also very prevalent, concerning up to $70 \%$ of adults with ADHD. ${ }^{5,6}$ Moreover, emotion dysregulation is among the clinical features predictive of a persistent course of ADHD symptoms in adults. ${ }^{7}$ 
ADHD symptoms in adulthood greatly interfere with daily functioning, and are associated with high number of psychiatric comorbidities ${ }^{3}$ Among them, borderline personality disorder (BPD) in particular is encountered far more often than expected by chance in adults with ADHD., BPD is characterized by a pervasive pattern of instability in affect regulation, impulse control, interpersonal relationships, and self-image that concerns $1-6 \%$ of the general population. ${ }^{3,9,10}$ BPD subjects are an heterogeneous group, with some subjects characterized by prominent dysexecutive and impulsive features, others by prominent affective or dissociative features. ${ }^{11,12}$ At least $14 \%$ of those diagnosed with ADHD in childhood later receive a diagnosis of BPD while between $18 \%$ and $34 \%$ of the adults with ADHD are estimated to have comorbid BPD. ${ }^{12-14}$ This along with the fact that BPD shares at least two of its symptomatic dimensions, i.e., impulsivity and emotion dysregulation, with adult $\mathrm{ADHD}^{15}$ has raised the question of the nature of the relationship between the two disorders ${ }^{16}$ The first two reviews focusing on this topic, ${ }^{17,18}$ published prior to the DSM-5 proposal of specific diagnostic criteria for adult ADHD, concluded that there was a significant association between adult BPD diagnoses and history of childhood ADHD symptoms assessed retrospectively, hence suggesting that ADHD could represent a developmental risk factor for BPD. Three more recent reviews by Matthies \& Philipsen ${ }^{19,20}$ and Storebø \& Simonsen ${ }^{16}$ highlighted the common clinical features of BPD and adult ADHD, including impulsivity and emotion dysregulation, and the more severe forms of patients presenting with both diagnoses. However, because the interest in the overlap between adult ADHD and BPD is fairly recent, previous reviews barely addressed the characterization of the comorbid ADHD+BPD form, and only few studies included in these reviews provided a direct comparison of the clinical and neuropsychological features common to adult ADHD and BPD. Our review thus aims at filling this gap, focusing on the recent data regarding the three clinical pictures in adults, especially the comorbid ADHD+BPD form. Of major importance, age of onset used to be a discriminative diagnostic criterion between ADHD, typically viewed as an early-onset neurodevelopmental disorder, and BPD, a lateonset psychological disorder. However, this distinction has been recently called into question, increasing the need for more research aiming at delineating the disorders from a developmental and clinical standpoint.

In this study we will present a narrative review of the available data regarding i) the prevalence of the co- occurrence of adult ADHD and BPD, ii) the clinical similarities and differences between the two groups, iii) their etiology, and iv) the developmental pathways potentially linking the two disorders. As noted above, we will focus on studies which included the adult ADHD+BPD group, and on etiological studies which might help clarifying the developmental risk factors for BPD and adult ADHD. It is crucial to gain a better understanding of the links between ADHD and BPD, to pinpoint treatment options for adults presenting with both diagnoses, but also to design early interventions to prevent the development of BPD in children and adolescents with ADHD symptoms who are at risk for BPD.

\section{Epidemiologic Data On The Association Between ADHD And BPD}

By the 1980s and early 1990s, while studies confirmed the boundaries of BPD relative to affective and psychotic disorders, they also highlighted its heterogeneity, with a significant subgroup of patients presenting with a history of developmental delay and attention disorder. ${ }^{11,21}$ Andrulonis et $\mathrm{al}^{22,23}$ found that $25 \%$ of a group of 106 BPD patients with IQs greater than 80 had a current or past history of ADHD and/or learning disabilities. Similarly, van Reekum et $\mathrm{al}^{21}$ reported that $27 \%$ of a group of 48 male veterans with BPD versus $6 \%$ of healthy controls had a history of ADHD. These results led the authors to suggest that there was an "organic" subgroup of patients with BPD presenting with frontal lobe dysfunction symptoms. Focusing specifically on childhood ADHD symptoms in adults with BPD, Fossati et $\mathrm{al}^{24}$ showed greater retrospectively assessed ADHD symptoms via the Wender Utah Rating Scale (WURS$25)^{25}$ compared to healthy controls and other personality disorders. Moreover, Fossati et $\mathrm{al}^{24}$ found that $60 \%$ of patients with BPD achieved WURS-25 scores deemed as suggestive of childhood ADHD. Another cross-sectional study by Speranza et $\mathrm{al}^{26}$ found $11 \%$ of ADHD in adolescent patients with BPD, and up to $46 \%$ of their sample presented at least one ADHD symptom which had some impact on functioning. Few studies have assessed the cooccurrence between ADHD and BPD longitudinally, which is crucial to understand the developmental relationship between the disorders. During the follow-up of hyperactive children into adulthood, Fischer et $\mathrm{al}^{27}$ reported that $14 \%$ of their sample had developed BPD vs $3 \%$ in the control group. Similarly, Miller et $\mathrm{al}^{28}$ examined the comorbidity of personality disorders longitudinally in adolescents 
diagnosed with ADHD between the ages of 7 and 11. The study found that individuals with childhood ADHD were significantly more likely to be diagnosed with BPD (13.5\% vs $1.2 \%$ in the control group, $\mathrm{OR}=13.16$ ) at the 16 to 26 year follow-up than the non-ADHD controls. Moreover, those who continued to meet diagnostic criteria for ADHD at follow-up had a higher rate of BPD diagnosis than those who remitted and controls (19\% in "persisters" vs $6.3 \%$ in "remitters"). In another longitudinal study, using latent growth curve models on two cohorts of girls annually assessed between the age of 8 and 14, Stepp et $\mathrm{al}^{29}$ found that higher levels of ADHD and Oppositional Defiant Disorder (ODD) scores at age 8 uniquely predicted BPD symptoms at age 14 .

Recent cross-sectional studies also showed a persistent course of ADHD symptoms in a high number of adults with BPD. In clinical samples of BPD patients screened for adult $\mathrm{ADHD}$, the prevalence of adult ADHD is higher than in the general population, ranging from $16.1 \%$ to $38.1 \% ;^{4,8,30-32}$ notably, women with ADHD, especially the combined type, have been reported to be more likely to have BPD than men with ADHD, whom more likely present with antisocial personality disorder. ${ }^{33}$ In forensic settings, Rösler et $\mathrm{al}^{34}$ found that female offenders with ADHD had BPD (63.6\%) more often than offenders without ADHD (25.3\%). Regarding population samples, results from the National Epidemiologic Survey on Alcohol and Related Conditions found that lifetime comorbidity in adults with BPD in the ADHD population was $33.7 \%$ compared with a lower prevalence of BPD of $5.2 \%$ in the general population. ${ }^{3}$

Altogether, a number of studies point to the fact that ADHD symptoms assessed retrospectively in patients with BPD occur more often than expected by chance and the co-occurrence of adult ADHD and BPD reported in several settings is high. Few studies have attempted to assess the co-occurrence between the disorders longitudinally, and found that childhood ADHD symptoms are significantly associated with an increased likelihood of BPD diagnosis in adulthood. ${ }^{28,29,35}$

\section{Psychopathological, Neuropsychological And Brain Mechanisms}

In order to improve the understanding between the cooccurrence of BPD and ADHD, a critical issue is the symptomatic overlap between the BPD and ADHD regarding two key clinical dimensions, ie, impulsivity and emotional dysregulation ${ }^{36}$ but also low self-esteem and disturbed interpersonal relationships which are common in both disorders. ${ }^{18}$

In one of the first studies investigating the specificity of the overall ADHD clinical dimensions in ADHD compared to BPD, Dowson et $\mathrm{al}^{36}$ found, using a self-report measure, that inattention, lack of organization and persistence differentiated ADHD from BPD alone, whereas interpersonal impairment did not. These results led the authors to conclude that their self-report scale was valid, as it assessed symptoms specifically found in ADHD. In two more recent studies however, Edebol et $\mathrm{al}^{37}$ and Weibel et $\mathrm{al}^{31}$ assessed the psychometric properties of the World Health Organization Adult ADHD Self-Report Scale v1.1 (ASRS-v1.1) and found that it lacked clinical specificity in adult ADHD (i.e., its ability to discriminate BPD alone from BPD+ADHD), a finding that was likely due to shared symptoms of emotion dysregulation and impulsivity. ${ }^{31}$ In addition, inattention may also be experienced in BPD, albeit in a special form as part of dissociative states, hence diminishing its power to discriminate the two disorders at least through self-report scales ${ }^{32}$

Somewhat similar results were found in a study by Philipsen et $\mathrm{al}^{38}$ when BPD symptoms were assessed in adult patients with ADHD using the Borderline Symptom List (BSL) ${ }^{39}$ Overall, lower scores were found in patients with ADHD compared to BPD patients, but scores in ADHD were higher on all subscales compared to healthy controls. Interestingly, particularly with respect to selfdestruction and affect dysregulation, borderline symptoms in adult ADHD seemed to be less pronounced than in patients with BPD. ${ }^{38}$

\section{Impulsivity}

Impulsivity has been identified as one of the dimensions having the greatest overlap between ADHD and BPD in adults ${ }^{40}$ Both ADHD and BPD report higher levels of traitimpulsivity compared to healthy controls when using selfreport measures such as the Barratt Impulsiveness Scale (BIS). ${ }^{26,41}$ Adults with ADHD+BPD and ADHD alone report however a higher level of trait-impulsivity compared to BPD alone ${ }^{12,26,42-44}$ and such is also the case for informant-rated impulsivity in ADHD+BPD compared to $\mathrm{ADHD}$ alone ${ }^{40}$ Impulsivity is a multi-faceted concept, and divergent findings have been reported across studies in terms of which dimensions show greater impairment in the three groups of patients. For instance, using the BIS, both 
Prada et $\mathrm{al}^{4}$ and Lampe et $\mathrm{al}^{44}$ found that motor impulsivity best distinguished ADHD and BPD+ADHD subjects from BPD alone, with the highest scores found in ADHD and BPD+ADHD. By contrast, Speranza et $\mathrm{al}^{26}$ showed, using the same scale, that higher levels of Attentional/ Cognitive trait-impulsivity were particularly associated with ADHD diagnosis in BPD adolescents. Using a selfreport measure, Dijk et $\mathrm{al}^{45}$ showed that high Novelty Seeking, which is related to impulsivity, was more strongly linked to ADHD than to BPD.

From a neuropsychological standpoint, impulsivity is assessed using a wide range of tasks targeting specific aspects of behavior control. ${ }^{46}$ Compared to healthy controls, adults with ADHD display impairment in most response inhibition paradigm studies ${ }^{47}$ whereas more conflicting findings have been reported in BPD, where inhibition impairment has been found mainly in emotionally conditioned tasks. ${ }^{48,49}$ Specifically, most studies have found delay discounting deficits in adults with BPD $;^{50,51}$ however, only some studies have observed impaired response inhibition in BPD patients compared to healthy participants, ${ }^{52,53}$ while others have not found significant differences. ${ }^{54,55}$ Few studies have compared cognitive inhibition performance in BPD, adult $\mathrm{ADHD}$, and $\mathrm{BPD}+\mathrm{ADHD}$ groups, and most have reported greater impairment in ADHD and ADHD+BPD compared to BPD alone (with one exception) ${ }^{56}$ In a first study, Nigg et $\mathrm{al}^{57}$ compared the performance of 105 adults with ADHD (of whom $20 \%$ with co-occurring BPD) and 90 healthy controls in the stop signal task, and found that response inhibition deficits were correlated to BPD symptoms. However, when ADHD symptoms were entered as a predictor, response inhibition ceased to be significantly associated with BPD symptoms. In another study, Lampe et $\mathrm{al}^{44}$ found that adults with ADHD performed worse than BPD individuals and healthy controls in two cognitive inhibition control tasks, while non-comorbid BPD subjects did not differ from their matched controls, suggesting that impaired inhibitory control is found in BPD+ADHD but not in BPD alone. In another study, O'Malley et $\mathrm{al}^{40}$ found greater attention and working memory impairment in adults with ADHD+BPD compared to non-comorbid ADHD, whereas inhibition of prepotent responses did not differ between groups, hence suggesting that the comorbid group presented with more severe cognitive impairment. Finally, in a series of studies, Krause-Utz et $\mathrm{al}^{46}$ Cackowski et al ${ }^{58}$ and Krause-Utz et $\mathrm{al}^{43}$ investigated the role of stress in different components of impulsivity in BPD compared to adult ADHD. In a first study, Krause-Utz et $\mathrm{al}^{46}$ proposed the Go/NoGo task before and after moderate stress induction in female adults with BPD alone, ADHD alone, BPD+ADHD, and female healthy controls. While ADHD and BPD+ADHD showed significantly more errors under stressful and non-stressful conditions, BPD did not differ from healthy controls. In a follow-up study by Cackowski et $\mathrm{al}^{58}$ BPD patients showed significantly impaired performance on a Stop-Signal task after severe stress induction, when including ADHD symptoms as a covariate. Krause-Utz et $\mathrm{a}^{43}$ replicated and expanded on these findings as they showed that, under severe stress only, BPD patients performed significantly worse than healthy controls, while ADHD showed significant action-withholding deficits under stressful and non-stressful conditions.

Functional neuroimaging data of frontal dysfunction of inhibitory control in BPD and ADHD are mostly consistent with the aforementioned behavioral results ${ }^{48}$ Indeed, overall, patients with BPD exhibit prefrontal dysfunctions in orbitofrontal, dorsomedial, and dorsolateral prefrontal regions when they perform impulse control tasks, whereas adults with ADHD display disturbed activity mainly in ventrolateral and medial prefrontal regions. This suggests a dissociation of frontal dysfunctions in BPD and ADHD, although only few studies have provided a direct comparison of these disorders and assessed different facets of inhibition control. ${ }^{48}$

Comparative data on impulsivity is scarce in ADHD, BPD, and BPD+ADHD. Nevertheless, the available results point to two directions: first, there might be a subgroup of individuals with BPD with high levels of trait-impulsivity, and those individuals seem to correspond to the comorbid BPD+ADHD type , $^{42,26,40}$ second, unlike ADHD, impulsivity in BPD might be intrinsically related to emotion dysregulation, that is, in highly stressful conditions, individuals with BPD exhibit more pronounced impulsive behaviors whereas in ADHD impulsive behaviors seem to be less stress-dependent. ${ }^{59}$

\section{Emotion Dysregulation}

Emotion dysregulation is a core mechanism of BPD concerning at least two of the DSM- 5 criteria for the disorder ${ }^{1}$ In terms of the dynamics of emotion dysregulation in BPD, a recent review of 34 studies using ecological momentary assessments found that BPD patients experience longer duration of aversive tension and a slower return to their baseline affective state ${ }^{60}$ Relative to BPD, in ADHD, emotion dysregulation has been understudied until recently, although it is a frequent symptom that is associated with poorer functioning outcomes, regardless of 
other psychiatric comorbidities. ${ }^{5,60-64}$ Research has shown that emotion dysregulation in ADHD is similar to that found in BPD, including increased instability and intensity of negative emotions and a slow return to emotional baseline when activated. ${ }^{62,64}$ However, to our knowledge, only three studies have directly compared emotion dysregulation in $\mathrm{ADHD}, \mathrm{BPD}$, and BPD+ADHD, with conflicting results. Cavelti et al $^{65}$ compared self-assessed trait emotion regulation skills in 80 adults with ADHD, 55 with BPD, and 55 healthy participants. The authors found no differences between the clinical groups on self-reported emotion regulation skills which were significantly worse than those reported by healthy controls. In another study, Cackowski et $\mathrm{al}^{66}$ found that adult ADHD and BPD patients scored significantly higher on all self-report measures of trait anger, anger expression, aggressive and antisocial behavior compared to healthy controls. Compared to ADHD patients, BPD patients reported higher trait aggression and hostility, as well as a stronger tendency to express anger when provoked, and to direct anger inwardly. Furthermore, after stress induction, BPD patients exhibited higher state anger than healthy controls and ADHD patients. Of particular interest, BPD patients reported more severe trait emotion dysregulation on the Difficulties in Emotion Regulation Scale (DERS) ${ }^{67}$ compared to healthy controls and ADHD patients, and emotion dysregulation was significantly associated with elevated self-reported proneness to anger and aggression. In a recent study, Rüfenacht et $\mathrm{al}^{60}$ found that adults with ADHD had significantly better self-reported emotion regulation strategies than patients with BPD alone, and BPD +ADHD. Specifically, adults with ADHD showed lower emotional reactivity, better use of adaptive cognitive strategies and lesser use of non-adaptive strategies compared to the two other groups.

Overall, trait emotion dysregulation is clearly overrepresented in ADHD compared to healthy controls, and it has been argued that it could be a key feature of the disorder $^{68}$ Like BPD, ADHD is a heterogeneous disorder, and it is likely that subgroups differ in terms of executive dysfunction ${ }^{69}$ but also of emotion regulation deficits $^{70}$ Consistent with this hypothesis, Hirsch et $\mathrm{al}^{70}$ recently found that empirically derived symptom profiles revealed two clusters of adult patients with ADHD: the first comprised substantial proportions of the inattentive and the combined subtype, and the second included patients with severe emotion dysregulation, higher psychosocial impairments, and more comorbidities, including personality disorders.

The neuropsychological underpinnings of emotion regulation deficits in ADHD and BPD are still mostly unknown $^{71}$ In ADHD, there are two main hypotheses: the "dyscontrol hypothesis" whereby emotion dysregulation is driven by the same cognitive and neural processes that drive ADHD, mainly deficits in top-down executive control; and the "affectivity hypothesis" that states that emotion dysregulation is related specifically to emotional regulation neural processes, separate from those that lead to ADHD symptoms ${ }^{72}$ To date the accumulating evidence is pointing to the affectivity hypothesis ${ }^{71}$ Regarding BPD, a critical review of fMRI studies concluded that emotion dysregulation was associated with increased amygdala activity and decreased activity within prefrontal regions, suggesting an impaired fronto-limbic inhibitory network ${ }^{73}$ In a recent review, Petrovic \& Castellanos ${ }^{74}$ proposed that the difference between ADHD and predominantly emotional instability disorders such as BPD is whether there is a dysfunctional top-down regulation of non-emotional (and exteroceptively associated) processing or emotional (and interoceptively associated) processing subtended respectively by (i) the rostral ACC and the lateral orbitofrontal cortex and (ii) the caudal anterior cingulate cortex (ACC) and the and dorsolateral prefrontal cortex. In this sense, they speculated that ADHD patients presenting with emotion dysregulation symptoms would have poor capacity for both non-emotional and emotional regulatory processing. A putative extreme situation of very low emotional regulatory processing associated with low nonemotional processing would lead to the comorbid BPD +ADHD. In this somehow dynamic perspective, Petrovic $\&$ Castellanos $^{74}$ proposed to view both disorders in a dimensional fashion as these neural systems are highly interdependent, and possibly modulated by the dopaminergic system. ${ }^{74}$

\section{Interpersonal Problems}

Interpersonal problems are often found in both BPD and $\mathrm{ADHD},{ }^{4,36}$ and are related to decreased quality of life and self-esteem found in both disorders. ${ }^{40,75-77}$ In BPD, interpersonal difficulties are a cardinal symptom of the disorder, defined by unstable and intense relationships with an alternation between idealization and devaluation, as well as high interpersonal sensitivity and efforts to avoid abandonment. ${ }^{1,77}$ In ADHD, interpersonal problems have been conceptualized as being consecutive to its core triad of symptoms inattention, 
impulsivity and hyperactivity as well as social cognition deficits, all of which might be interpreted in the context of frontostriatal dysfunction ${ }^{78}$ A number of studies have shown that interpersonal difficulties in BPD are related to both emotion dysregulation and impulsivity, but also to mentalizing abnormalities, that is, the ability to comprehend one's own and others' behavior in terms of intentional mental states ${ }^{77}$ For instance, Herr et $\mathrm{al}^{79}$ found that the association between overall BPD symptomatology and interpersonal problems was fully mediated by emotion regulation deficits. More recently, emotion dysregulation and attentional impulsiveness were shown to predict interpersonal problems directly in adult BPD subjects, whereas hypomentalizing predicted interpersonal problems indirectly throughout emotion dysregulation and attentional impulsiveness ${ }^{77}$ These results hence suggested that targeting emotion dysregulation, impulsivity, and mentalization might impact interpersonal problems in BPD. In adult ADHD, the mechanisms involved in interpersonal problems have been less studied. ${ }^{78,80}$ Although young adults with ADHD report having higher levels of interpersonal problems relative to healthy controls, they tend to underreport hostile interpersonal problems ${ }^{82}$ probably due to mentalization deficit and reduced empathy. ${ }^{61,80}$ To our knowledge, only two studies have directly compared adult ADHD, BPD, and BPD+ADHD on mentalization and empathy skills. In a first study, participants with ADHD showed self-reported mentalization scores mid-point between healthy controls and participants with BPD. Interestingly, those with comorbid BPD+ADHD achieved the lowest mentalization scores of all groups, and the severity of ADHD symptoms was correlated with poorer mentalization levels in all clinical groups ${ }^{80}$ In another recent study, Rüfenacht et $\mathrm{al}^{61}$ found that $\mathrm{ADHD}$ as well as BPD subjects displayed lower self-reported empathy than a sample of healthy subjects, a finding interpreted as being related in both cases to emotion dysregulation and mentalizing difficulties. The authors thus speculated that targeting protective mentalization and emotion dysregulation early in development may help prevent the persistence of ADHD into adulthood and the emergence of comorbid mood and personality disorders. ${ }^{61}$

\section{Etiological Factors}

Early theoretical models of BPD emphasized the role played by childhood sexual abuse as a major risk (and etiological) factor for $\mathrm{BPD}^{81}$ It has since been recognized that severe abuse occurs only in a minority of BPD patients, with a small effect size $\mathrm{e}^{82}$ and that childhood maltreatment is a non-specific risk factor for a diverse range of disorders ${ }^{83}$ Such is the case for adult ADHD, where childhood emotional abuse and neglect are more commonly reported relative to healthy controls ${ }^{84}$ Most evidence now supports gene-environment interaction and correlation in the development of both BPD and ADHD, ${ }^{85,86}$ with different heritability rates for each disorder. ${ }^{87,88}$ This means that individuals with a "sensitive" genotype are at greater risk in the presence of a predisposing environment.

\section{Genetic Studies}

While it is firmly established that genetic factors play a central role in the etiology of ADHD, with heritability estimates ranging between $70-80 \%{ }^{87}$ the literature in BPD remains relatively underdeveloped in this field. Familial and twin studies indicate a genetic component to adult BPD, with heritability estimates ranging from $35 \%$ to $46 \%{ }^{88-90}$ although no gene has been identified to date. ${ }^{88,89}$ Only two studies have investigated the shared genetic and environmental contributions to ADHD and BPD. In a first study, Distel et $\mathrm{al}^{86}$ investigated ADHD and borderline symptoms in a sample of 7,233 twins and siblings in the Netherlands; results showed that half of the association between ADHD and BPD was explained by genetic factors, while the remaining part of the association was due to environmental factors unique to the individual. Recently, Kuja-Halkola et $\mathrm{al}^{90}$ explored familial co-aggregation of clinically diagnosed ADHD and BPD from a sample of $2,113,902$ individuals registered in a cohort study in Sweden. The authors found that individuals with a diagnosis of ADHD had 19.4 times higher odds of BPD diagnosis than individuals not diagnosed with ADHD. Moreover, the pattern of familial co-aggregation of ADHD and BPD across different types of relatives indicated that genetic factors were involved in ADHD and BPD co-occurrence. Interestingly, Mistry et al $^{91}$ recently reported that polygenic risk score for bipolar disorder was strongly linked to childhood ADHD, but not to BPD traits, suggesting different genetic background for ADHD and BPD.

\section{Developmental Pathways And The Role Of Temperament And Traumatic Events} Early- Or Late-Onset Disorders?

The most supported pathogenesis theory of BPD is the one proposed by Linehan ${ }^{15}$ which suggests that BPD results from the interactions between biological and psychosocial factors ${ }^{81}$ in particular between biologically based temperamental vulnerabilities and adverse and traumatic experiences during childhood. Age of onset of BPD is a controversial topic, but 
most research now considers that BPD diagnosis may be established in adolescence, ${ }^{26,92}$ and symptoms by the age of 12 predict psychosocial functioning during the transition to adulthood $^{92}$ This highlights the genetic component involved in the pathogenesis of BPD, which had been overshadowed by earlier models that focused solely on environmental risk factors for the disorder. ${ }^{81,92}$ From a lifespan perspective, there is evidence that the prevalence of BPD symptomology decreases with age $\mathrm{e}^{93,94}$ and that older adults are less likely than younger adults to endorse specific BPD symptoms such as impulsivity, self-harm/suicidality and affective and interpersonal instability ${ }^{95}$ By contrast, ADHD is usually viewed as a neurodevelopmental disorder: symptoms must be present before the age of $12^{1}$ and are mostly stable across time, though some decline in adulthood has been reported ${ }^{96}$ Recently however, the neurodevelopmental basis of ADHD has been called into question, as in three birth cohorts followed up until adulthood, a vast majority of those with adult ADHD did not have significant ADHD symptoms during childhood, and the overlap between ADHD diagnosed in childhood and ADHD diagnosed in adults was low. ${ }^{97-99}$ Thus, these results indicate that either adult-onset ADHD is a distinct clinical entity ${ }^{100}$ or the developmental pathways involved in early- and late-onset ADHD differ while sharing the same genetic, environmental and underlying neural mechanisms, due to fluctuating environment pressure or preventive factors ${ }^{101}$ Importantly, it is still unknown whether age of onset of symptoms is involved in the likelihood of presenting with the comorbid ADHD+BPD clinical picture in adulthood. Van Dijk et $\mathrm{al}^{102}$ showed, using latent class analyses, that some cases of comorbid ADHD+BPD symptoms in adults were not preceded by significant childhood ADHD symptoms, consistent with the late-onset ADHD construct. However, predominant BPD symptoms could be traced back to ADHD symptoms in childhood, especially hyperactivity/impulsivity symptoms. The authors thus concluded that there were two possible developmental pathways: the first leading from combined ADHD symptoms in childhood to adult ADHD, and the second leading from childhood hyperactive/impulsive symptoms to an adult profile of ADHD +BPD symptoms.

\section{Temperament}

Temperament has been conceptualized as a genetically influenced building block of personality; it has been shown to be highly heritable and relatively stable across the lifespan ${ }^{103}$ ADHD and BPD share a number of temperament traits, especially novelty seeking and harm avoidance $^{104}$ Novelty seeking, a construct closely related to impulsiveness, has been associated with $\mathrm{BPD}^{105}$ in male patients in particular ${ }^{106}$ whereas harm avoidance has been reported in female patients with $\mathrm{BPD}^{106}$ Similarly, in ADHD, novelty seeking has been found to predict ADHD diagnosis ${ }^{103}$ and increased harm avoidance has also been reported in $\mathrm{ADHD}^{104}$ In a recent systematic review on temperament correlates in adult ADHD, Pinzone et al $^{107}$ found high scores on the Novelty Seeking and Harm Avoidance subscales and low scores on the Persistence subscale of the Temperament and Character Inventory (TCI) ${ }^{108}$ compared to healthy controls. Using the Temperament Evaluation of Memphis, Paris and San Diego-Auto-questionnaire (TEMPS-A) ${ }^{109}$ which assesses affective temperaments derived from a kraepelinian framework, the authors found that the majority of ADHD individuals shared temperament traits such as cyclothymia and irritability with patients with bipolar disorder, but not hyperthymia. Importantly, both BPD and ADHD disorders are highly comorbid with bipolar disorder, ${ }^{110,111}$ a finding that has raised the question of whether this overlap is also found at the temperament level ${ }^{111}$ Although it is beyond the scope of this review to include findings relative to bipolar disorder, it is noteworthy that similar cyclothymic temperament traits levels, which are related to affective instability, have been reported in BPD, ADHD and bipolar disorder, suggesting that affective instability is a core temperament dimension shared by the three ${ }^{111}$ Few other studies have directly compared temperament traits in BPD, adult ADHD, and BPD+ADHD. In one of them, van Dijk et $\mathrm{al}^{45}$ found that high Novelty Seeking was particularly associated with inattention symptoms of ADHD, and the highest Novelty Seeking temperament scores were found in ADHD+BPD. By contrast, high Harm Avoidance, low Cooperativeness, and low Self-directedness were specifically related to BPD symptoms. In another study, Carlotta et $\mathrm{al}^{112}$ found that action-oriented features - ie, impulsivity, aggression, novelty seeking, and juvenile conduct problems - completely mediated the relationship between retrospective ADHD symptoms and current BPD features, suggesting that impulsivity might be particularly involved in the cooccurrence of BPD and ADHD.

\section{Adverse And Traumatic Experiences}

The most supported theory of BPD posits that the disorder occurs in the context of an interaction between temperamental traits, especially impulsivity and emotion dysregulation, and an invalidating childhood environment 
characterized by intolerance toward the expression of private emotional experiences ${ }^{15}$ Children exposed to such adverse environments are therefore unable to learn how to effectively regulate their emotions, and they vacillate between emotional inhibition and extreme emotional lability ${ }^{15}$ Several studies have shown that BPD is associated with childhood abuse and neglect more than any other personality disorder, ${ }^{93,113}$ and emotion regulation difficulties have been shown to be key mediators in the relationship between childhood trauma and $\mathrm{BPD}^{114}$ As outlined above however, adverse and traumatic events are very prevalent in personality disorders as a whole ${ }^{115}$ but also in ADHD as well as in other psychiatric disorders ${ }^{116}$ For instance, a recent cohort study in Sweden found an increased risk for ADHD (OR 5.5, 95\% CI 5.0-6.0) in individuals who had been repeatedly exposed to childhood adversity ${ }^{116}$ Given this, a critical issue is whether the same type of adverse and traumatic events is involved in the pathogenesis of BPD, ADHD, and BPD+ADHD. In one of the first studies investigating this topic, Philipsen et $\mathrm{al}^{8}$ found higher rates of emotional abuse in BPD females with childhood ADHD symptomatology compared to those who had few childhood ADHD symptoms, and this was associated in turn with more severe borderline symptomatology in adulthood. Sexual and physical abuse did not distinguish the two groups of BPD patients. Recently, Ferrer et al ${ }^{117}$ reported that physical abuse in childhood was associated with the persistence of ADHD into adulthood, while emotional or sexual abuse was predictive of development of BPD or comorbid BPD+ADHD, hence highlighting that specific traumatic events could increase the likelihood of developing either $\mathrm{ADHD}$ alone or $\mathrm{BPD}$ and $\mathrm{BPD}+\mathrm{ADHD}$. In another recent study, Richard-Lepouriel et al ${ }^{42}$ compared self-reported childhood traumatic events in BPD, adult ADHD, bipolar disorder and healthy adults. Relative to adult ADHD, BPD patients had higher scores for emotional and sexual abuse; for sexual abuse in particular, BPD patients had higher scores than any another population. Scores were higher in ADHD compared to healthy controls in all subscales of the Childhood Trauma Questionnaire (CTQ) ${ }^{118}$ except for sexual abuse, while relative to bipolar disorder, adults with ADHD showed higher scores for emotional and physical abuse, but also physical neglect. Of note, female gender has been reported to predict the developmental progression of childhood ADHD to adult BPD $^{119}$ a finding that may be due to the fact that sexual abuse in childhood is more prevalent among women, on the one hand, and that sexual abuse is a vulnerability risk for
$\mathrm{BPD}^{119}$ One possibility is that, in genetically susceptible individuals, early-life exposure to adversity may alter trajectories of brain development and increase the vulnerability to psychopathology. Severe childhood maltreatment, especially sexual abuse, is thought to be involved in the precursors of borderline symptoms through its impact on hippocampal volume, amygdala reactivity, and the development of frontal lobe functions in particular, which is involved in self-control and emotion regulation. ${ }^{120,121}$ It has been argued that during early childhood the prefrontal cortex forms the basic neural circuitry (through synaptic production) that is modified in adolescence (synaptic pruning) ${ }^{122}$ Since the prefrontal cortex subtends attention control abilities, it is unsurprising that maltreated children will be more likely to present attention and executive dysfunction, consistent with a diagnosis of $\mathrm{ADHD}^{122}$ It is still unknown however whether the phenomenology of attention and executive dysfunction in these individuals differs from those who present with ADHD and fewer childhood adversity events. We speculate that emotional and sexual childhood abuse in particular might be involved in the emergence of symptoms of BPD, such as dissociative states and emotion dysregulation.

In addition to different types of adversity, timing of exposure during different developmental periods could be an important factor for differential disease risk ${ }^{123}$ and could be mediated by differential vulnerability of certain systems during developmental periods ${ }^{124}$ This means that investigating the differential disease risk relative to type of adversity, but also timing of exposure in BPD, ADHD, and BPD+ADHD could be particularly relevant to the understanding of their specific developmental pathways.

Given the increasing evidence supporting the role played by adverse and traumatic events on the emergence of psychopathology ${ }^{124}$ there has been a shift in ongoing research in psychiatric disorders from identifying "vulnerability genes" to identifying genes that can be influenced by the environment and contribute to adult psychopathology ${ }^{125}$ Epigenetics, which refer to the study of modifications of gene expression rather than alteration of the genetic code itself, has been investigated in relation to childhood adversities mainly in BPD. Genes involved in the regulation of the hypothalamic-pituitary-adrenal (HPA) axis have shown promising results ${ }^{126}$ However few studies have investigated this issue in ADHD and few epigenetic changes in relation to early life adversities have been shown to be shared between ADHD and BPD. ${ }^{125}$ 


\section{Discussion}

Over the last decades, interest in the relationship between ADHD and BPD has increased, owing to the growing number of studies that have reported high rates of comorbid BPD+ADHD, and the poorer functioning found in the comorbid form ${ }^{4}$ Four possible explanations as to why the two disorders frequently co-occur have been put forward: i) ADHD may be a developmental precursor of BPD; ii) BPD and ADHD may correspond to different expressions of the same disorder rather than two distinct clinical entities; iii) ADHD and BPD may be distinct disorders sharing common etiological risk factors; and iv) the presence of one disorder may increase the risk of developing the other. ${ }^{4,16}$ The phenotypic overlap between the two disorders, as well as the high rates of co-occurrence and familial aggregation, support the role played by shared risk factors. ${ }^{90,112}$ This points to the fact that symptoms should be considered dimensionally and an important focus should be put on the developmental pathways involved in their emergence and persistence. Importantly, the boundaries between BPD and ADHD have become less clear over the last two decades, with research showing that adverse childhood events might increase the risk of developing ADHD, ${ }^{84,116}$ and that borderline symptoms predictive of adult BPD diagnosis can be traced back to childhood. $^{92}$ This highlights the need for more research into the developmental pathways involved in the emergence of both disorders. Traditionally, BPD and ADHD were conceptualized as either a late-onset and traumarelated disorder (for BPD) or an early-onset neurodevelopmental disorder (for ADHD). Our review highlights the recent shift toward a diathesis biopsychosocial model whereby both biological and environmental factors are involved in the pathogenesis of BPD and ADHD. This bears some important clinical and research implications as there are probably neurodevelopmental aspects involved in the emergence of BPD, and there are environmental aspects involved in the emergence and/or the persistence of ADHD in adults.

Both in BPD and ADHD, phenotypic expressions are heterogeneous with some overlap between the two disorders at the dimensional level. The determinants of this heterogeneity are still largely unknown, making the available diagnostic categories imperfect. From a dimensional perspective, our review highlights that the co-occurrence between ADHD and BPD might be explained by two major shared dimensions - i.e., impulsivity and emotion dysregulation - probably subtended by differential dysfunction of top-down regulation of emotional and nonemotional processing ${ }^{74}$ Importantly, although impulsivity and emotion dysregulation are shared by ADHD and BPD, trait-impulsivity is higher in ADHD and ADHD+BPD compared to $\mathrm{BPD}$ alone, and trait-emotion dysregulation is higher in BPD and ADHD+BPD compared to ADHD, hence suggesting that in BPD impulsivity and emotion dysregulation are intrinsically related. ${ }^{58,74}$ This means that, phenomenologically speaking, there might be differences in the way impulsivity and emotion dysregulation are expressed in BPD and ADHD alone; by focusing on these differences, clinicians might increase diagnostic specificity.

Historically, BPD has been considered as a psychological disorder whose first-line treatment is psychotherapy ${ }^{127}$ Conversely, ADHD has been conceptualized as a neurodevelopmental disorder, whose treatment mainly relies on psychostimulant drugs ${ }^{32}$ Both tend to be diagnosed and treated by specialists with expertise exclusively in one of the two disorders. Diagnosing adult ADHD might be difficult, especially when emotion dysregulation symptoms are present, and treatment of BPD patients requires well-trained therapists. Because of this, it is crucial that clinicians systematically inquire about the potential comorbidity. However, despite the importance of screening for ADHD in the context of BPD (and vice-versa), screening tools lack the ability to discriminate ADHD in BPD patients ${ }^{31}$ and to our knowledge, the psychometric properties of BPD screening measures in adult ADHD have yet to be investigated. Therefore, clinicians should not rely on screening measures alone to make a diagnosis; instead, clinicians working in each field (BPD and ADHD) should be knowledgeable of the other field in order to effectively detect comorbid cases in clinical practice, based on the careful intake of the patient's psychiatric and developmental history.

Developmentally speaking, our review indicates that a subgroup of patients with childhood ADHD has relatively few emotion dysregulation symptoms, and they also have a lower risk of having a persistent ADHD clinical picture and developing BPD in adulthood. ${ }^{70,71}$ Another subgroup, probably characterized by higher levels of hyperactivity/ impulsivity and emotional problems, seems more prone to develop the comorbid BPD+ADHD clinical presentation ${ }^{70}$ It is unclear to what extent these clinical pictures are linked to either different neurobiological vulnerabilities, and/or their interaction with an unfavorable environment. Emerging evidence on the latter topic suggests that while 
childhood adversity may increase the risk of overall psychopathology $^{124}$ it is likely that repeated exposure to physical abuse in particular might be associated with the persistence of ADHD into adulthood, while emotional or sexual abuse might be particularly involved in the development of $\mathrm{BPD}$ or comorbid $\mathrm{BPD}+\mathrm{ADHD}^{117}$ Moreover, although still speculative, it is possible that ADHD symptoms in childhood, especially when untreated, may increase the odds of severe negative childhood experiences, and this, in turn, may predispose to the development of BPD in adulthood in a subgroup of individuals. ${ }^{8}$

Given that adult $\mathrm{ADHD}$ and $\mathrm{BPD}$ share a range of warning signs and risk factors, when focusing on the developmental pathways involved in the emergence of both disorders, it might be useful to consider ADHD and BPD dimensionally rather than as two categorical entities. Shared warning signs include impulsivity and anger, which have been found to be trait-like dimensions of $\mathrm{BPD}^{10}$ as well as some of the main mediators of ADHD symptoms in childhood and BPD diagnosis in adulthood ${ }^{112}$ In addition, emotion regulation difficulties have been shown to be key mediators in the relationship between childhood trauma and $\mathrm{BPD}^{114}$ These results point to fact that if we are to design effective early preventive interventions in ADHD and BPD, those should be cross-diagnostic and based on clinical staging (ie, the severity and persistence of specific symptoms) instead of focusing on diagnostic categories and arbitrary age restrictions (i.e., early-onset for ADHD, and late-onset for BPD). ${ }^{10}$

In terms of treatment, there are several unmet needs that should be addressed. Treatment by psychostimulants in comorbid ADHD and BPD has only been tested in open trials $^{128}$ Furthermore, one non-randomized open study showed that psychostimulants improved response to psychotherapy in patients with the comorbid BPD+ADHD form $^{129}$ In ADHD alone, dialectical behavioral therapy (DBT) targeting emotion dysregulation has shown some encouraging effects in terms of global functioning. ${ }^{130-132}$ Overall, despite the lack of robust evidence supporting the use of psychostimulants and psychotherapy in BPD $+\mathrm{ADHD}$, this has been recommended by experts based on clinical experience ${ }^{32}$ It is noteworthy that the moderating impact of the comorbidity has not been investigated in randomized controlled trial of psychotherapeutic treatments for BPD and pharmacological treatments for ADHD. Such studies are warranted in order to improve the understanding of how clinical heterogeneity, especially in terms of
Table I Keypoints And Suggested Directions For Research

- Adult ADHD and BPD are heterogeneous disorders that can no longer be viewed as purely early-onset neurodevelopmental (ADHD) or late-onset psychological disorders (BPD)

- Comorbid adult ADHD+BPD is frequent in clinical settings (16.1$38 \%$ of BPD patients)

- The ADHD+BPD form is characterized by a more severe clinical presentation, i.e., higher trait-impulsiveness compared to BPD alone, and higher emotion dysregulation compared to ADHD alone

- Pathogenesis of ADHD and BPD involves some shared genetic, temperamental and environmental vulnerability factors, including childhood adversity

- Screening tools lack discriminative power in clinical settings, probably due to the shared symptomatic expressions between ADHD and BPD (e.g., emotion dysregulation and impulsiveness)

- Research is needed:

- To prospectively assess whether and how childhood ADHD symptoms increase the risk for BPD in adults

- To determine how the timing and the type of childhood adversity might differentially impact the development of ADHD, BPD, and ADHD+BPD in genetically susceptible individuals

- To identify children and adolescents at risk for the development of adult ADHD, BPD, and ADHD+BPD in order to design effective early interventions

- To assess the effectiveness of pharmacological and psychological interventions for comorbid cases

comorbid symptoms, impact treatment response. Main conclusions of the review are summarized in Table 1.

All in all, our study highlighted the overlap between BPD and ADHD, which is observed not only at the clinical level - that is, in terms of clinical expression, risk factors and particular developmental pathways but also at the therapeutic level. This means that clinicians working with ADHD or BPD have to be particularly aware of their potential comorbidity and what it implies in terms of prognosis and treatment. Of particular clinical relevance, ADHD and BPD can no longer be viewed as either exclusively neurodevelopmental or psychological disorders. This has important clinical implications as preventive interventions should address trait-dimensions as well as environmental risk factors shared by ADHD and BPD in childhood, in order to improve the outcomes of individuals at risk.

\section{Disclosure}

The authors report no conflicts of interest in this work. 


\section{References}

1. Association AP. Diagnostic and Statistical Manual of Mental Disorders $\left(D S M-5^{\circledR}\right)$. American Psychiatric Pub; 2013.

2. Kessler RC, Adler L, Barkley R, et al. The prevalence and correlates of adult ADHD in the United States: results from the National Comorbidity Survey Replication. Am J Psychiatry. 2006;163 (4):716-723. doi:10.1176/ajp.2006.163.4.716

3. Bernardi S, Faraone SV, Cortese S, et al. The lifetime impact of attention-deficit hyperactivity disorder: results from the National Epidemiologic Survey on Alcohol and Related Conditions. Psychol Med. 2012;42(4):875. doi:10.1017/S003329171100153X

4. Prada P, Hasler R, Baud P, et al. Distinguishing borderline personality disorder from adult attention deficit/hyperactivity disorder: a clinical and dimensional perspective. Psychiatry Res. 2014;217 (1):107-114. doi:10.1016/j.psychres.2014.03.006

5. Corbisiero S, Stieglitz R-D, Retz W, Rösler M. Is emotional dysregulation part of the psychopathology of ADHD in adults? ADHD Atten Deficit Hyperact Disord. 2013;5(2):83-92. doi:10.1007/ s12402-012-0097-z

6. Shaw P, Stringaris A, Nigg J, Leibenluft E. Emotional dysregulation and attention-deficit/hyperactivity disorder. Am J Psychiatry. 2014;171(3):276-293. doi:10.1176/appi.ajp.2013.13070966

7. Biederman J, Spencer TJ, Petty C, et al. Longitudinal course of deficient emotional self-regulation CBCL profile in youth with ADHD: prospective controlled study. Neuropsychiatr Dis Treat. 2012;8:267-276. doi:10.2147/NDT.S29670

8. Philipsen A, Limberger MF, Lieb K, et al. Attention-deficit hyperactivity disorder as a potentially aggravating factor in borderline personality disorder. Br J Psychiatry J Ment Sci. 2008;192(2):118123. doi:10.1192/bjp.bp.107.035782

9. Lieb K, Zanarini MC, Schmahl C, Linehan MM, Bohus M. Borderline personality disorder. Lancet Lond Engl. 2004;364 (9432):453-461. doi:10.1016/S0140-6736(04)16770-6

10. Chanen A, Sharp C, Hoffman P. Prevention and early intervention for borderline personality disorder: a novel public health priority. World Psychiatry. 2017;16(2):215-216. doi:10.1002/wps.20429

11. Andrulonis PA, Glueck BC, Stroebel CF, Vogel NG. Borderline personality subcategories. J Nerv Ment Dis. 1982;170(11):670-679. doi:10.1097/00005053-198211000-00006

12. Jacob CP, Romanos J, Dempfle A, et al. Co-morbidity of adult attention-deficit/hyperactivity disorder with focus on personality traits and related disorders in a tertiary referral center. Eur Arch Psychiatry Clin Neurosci. 2007;257(6):309-317. doi:10.1007/ s00406-007-0722-6

13. Matthies S, van Elst LT, Feige B, et al. Severity of childhood attention-deficit hyperactivity disorder-a risk factor for personality disorders in adult life? J Personal Disord. 2011;25(1):101-114. doi:10.1521/pedi.2011.25.1.101

14. Rasmussen P, Gillberg C. Natural outcome of ADHD with developmental coordination disorder at age 22 years: a controlled, longitudinal, community-based study. J Am Acad Child Adolesc Psychiatry. 2000;39(11):1424-1431. doi:10.1097/00004583-20001 1000-00017

15. Linehan MM. Cognitive-Behavioral Treatment of Borderline Personality Disorder. New York: Guilford Press; 1993.

16. Storebø OJ, Simonsen E. Is ADHD an early stage in the development of borderline personality disorder? Nord J Psychiatry. 2014;68(5):289-295. doi:10.3109/08039488.2013.841992

17. Davids E, Gastpar M. Attention deficit hyperactivity disorder and borderline personality disorder. Prog Neuropsychopharmacol Biol Psychiatry. 2005;29(6):865-877. doi:10.1016/j.pnpbp.2005.04.033

18. Philipsen A. Differential diagnosis and comorbidity of attentiondeficit/hyperactivity disorder (ADHD) and borderline personality disorder (BPD) in adults. Eur Arch Psychiatry Clin Neurosci. 2006;256(1):i42-i46. doi:10.1007/s00406-006-1006-2
19. Matthies SD, Philipsen A. Common ground in Attention Deficit Hyperactivity Disorder (ADHD) and Borderline Personality Disorder (BPD)-review of recent findings. Borderline Personal Disord Emot Dysregulation. 2014;1:3. doi:10.1186/ 2051-6673-1-3

20. Matthies S, Philipsen A. Comorbidity of Personality Disorders and Adult Attention Deficit Hyperactivity Disorder (ADHD)-review of recent findings. Curr Psychiatry Rep. 2016;18(4):33. doi:10.1007/ s11920-016-0675-4

21. van Reekum R, Conway CA, Gansler D, White R, Bachman DL. Neurobehavioral study of borderline personality disorder. $J$ Psychiatry Neurosci. 1993;18(3):121-129.

22. Andrulonis PA, Glueck BC, Stroebel CF, Vogel NG, Shapiro AL, Aldridge DM. Organic brain dysfunction and the borderline syndrome. Psychiatr Clin North Am. 1981;4(1):47-66. doi:10.1016/ S0193-953X(18)30936-5

23. Andrulonis PA, Vogel NG. Comparison of borderline personality subcategories to schizophrenic and affective disorders. $\mathrm{Br} J$ Psychiatry J Ment Sci. 1984;144:358-363. doi:10.1192/bjp.144.4.358

24. Fossati A, Novella L, Donati D, Donini M, Maffei C. History of childhood attention deficit/hyperactivity disorder symptoms and borderline personality disorder: a controlled study. Compr Psychiatry. 2002;43(5):369-377. doi:10.1053/comp.2002.34634

25. Ward MF, Wender PH, Reimherr FW. The Wender Utah Rating Scale: an aid in the retrospective diagnosis of childhood attention deficit hyperactivity disorder. Am J Psychiatry. 1993;150(6):885890. doi:10.1176/ajp.150.6.885

26. Speranza M, Revah-Levy A, Cortese S, Falissard B, Pham-Scottez A, Corcos M. ADHD in adolescents with borderline personality disorder. BMC Psychiatry. 2011;11(1):158. doi:10.1186/1471-244 $\mathrm{X}-11-158$

27. Fischer M, Barkley RA, Smallish L, Fletcher K. Young adult follow-up of hyperactive children: self-reported psychiatric disorders, comorbidity, and the role of childhood conduct problems and teen CD. J Abnorm Child Psychol. 2002;30(5):463-475. doi:10.102 3/A:1019864813776

28. Miller CJ, Flory JD, Miller SR, Harty SC, Newcorn JH, Halperin JM. Childhood attention-deficit/hyperactivity disorder and the emergence of personality disorders in adolescence: a prospective follow-up study. J Clin Psychiatry. 2008;69(9):1477-1484.

29. Stepp SD, Burke JD, Hipwell AE, Loeber R. Trajectories of attention deficit hyperactivity disorder and oppositional defiant disorder symptoms as precursors of borderline personality disorder symptoms in adolescent girls. J Abnorm Child Psychol. 2012;40(1):720. doi:10.1007/s10802-011-9530-6

30. Ferrer M, Andión O, Matalí J, et al. Comorbid attention-deficit/ hyperactivity disorder in borderline patients defines an impulsive subtype of borderline personality disorder. J Personal Disord. 2010;24(6):812-822. doi:10.1521/pedi.2010.24.6.812

31. Weibel S, Nicastro R, Prada P, et al. Screening for attention-deficit/ hyperactivity disorder in borderline personality disorder. $J$ Affect Disord. 2018;226:85-91. doi:10.1016/j.jad.2017.09.027

32. Asherson P, Young AH, Eich-Höchli D, Moran P, Porsdal V, Deberdt W. Differential diagnosis, comorbidity, and treatment of attention-deficit/hyperactivity disorder in relation to bipolar disorder or borderline personality disorder in adults. Curr Med Res Opin. 2014;30(8):1657-1672. doi:10.1185/03007995.2014.915800

33. Cumyn L, French L, Hechtman L. Comorbidity in adults with attention-deficit hyperactivity disorder. Can J Psychiatry Rev Can Psychiatr. 2009;54(10):673-683. doi:10.1177/07067437090540 1004

34. Rösler M, Retz W, Yaqoobi K, Burg E, Retz-Junginger P. Attention deficit/hyperactivity disorder in female offenders: prevalence, psychiatric comorbidity and psychosocial implications. Eur Arch Psychiatry Clin Neurosci. 2009;259(2):98-105. doi:10.1007/ s00406-008-0841-8 
35. Smith TE, Samuel DB. A multi-method examination of the links between ADHD and personality disorder. $J$ Personal Disord. 2017;31(1):26-48. doi:10.1521/pedi_2016_30_236

36. Dowson JH, McLean A, Bazanis E, et al. The specificity of clinical characteristics in adults with attention-deficit/hyperactivity disorder: a comparison with patients with borderline personality disorder. Eur Psychiatry J Assoc Eur Psychiatr. 2004;19(2):72-78. doi:10.1016/j.eurpsy.2003.07.010

37. Edebol H, Helldin L, Norlander T. Objective measures of behavior manifestations in adult ADHD and differentiation from participants with bipolar II disorder, borderline personality disorder, participants with disconfirmed ADHD as well as normative participants. Clin Pract Epidemiol Ment Health CP EMH. 2012;8:134-143. doi:10.2174/1745017901208010134

38. Philipsen A, Feige B, Hesslinger B, et al. Borderline typical symptoms in adult patients with attention deficit/hyperactivity disorder. Atten Deficit Hyperact Disord. 2009;1(1):11-18. doi:10.1007/ s12402-009-0001-7

39. Bohus M, Limberger MF, Frank U, Chapman AL, Kühler T, Stieglitz R-D. Psychometric properties of the Borderline Symptom List (BSL). Psychopathology. 2007;40(2):126-132. doi:10.1159/000098493

40. O’Malley GK, McHugh L, Mac Giollabhui N, Bramham J. Characterizing adult attention-deficit/hyperactivity-disorder and comorbid borderline personality disorder: ADHD symptoms, psychopathology, cognitive functioning and psychosocial factors. Eur Psychiatry J Assoc Eur Psychiatr. 2016;31:29-36. doi:10.1016/j. eurpsy.2015.09.012

41. Patton JH, Stanford MS, Barratt ES. Factor structure of the Barratt impulsiveness scale. J Clin Psychol. 1995;51(6):768-774. doi:10.1002/1097-4679(199511)51:6<768::aidjclp2270510607>3.0.co;2-1

42. Richard-Lepouriel H, Kung A-L, Hasler R, et al. Impulsivity and its association with childhood trauma experiences across bipolar disorder, attention deficit hyperactivity disorder and borderline personality disorder. J Affect Disord. 2019;244:33-41. doi:10.1016/j.jad.2018.07.060

43. Krause-Utz A, Cackowski S, Daffner S, et al. Delay discounting and response disinhibition under acute experimental stress in women with borderline personality disorder and adult attention deficit hyperactivity disorder. Psychol Med. 2016;46(15):31373149. doi:10.1017/S0033291716001677

44. Lampe K, Konrad K, Kroener S, Fast K, Kunert HJ, Herpertz SC. Neuropsychological and behavioural disinhibition in adult ADHD compared to borderline personality disorder. Psychol Med. 2007;37 (12):1717-1729. doi:10.1017/S0033291707000517

45. van Dijk FE, Lappenschaar M, Kan CC, Verkes RJ, Buitelaar JK. Symptomatic overlap between attention-deficit/hyperactivity disorder and borderline personality disorder in women: the role of temperament and character traits. Compr Psychiatry. 2012;53 (1):39-47. doi:10.1016/j.comppsych.2011.02.007

46. Krause-Utz A, Sobanski E, Alm B, et al. Impulsivity in relation to stress in patients with borderline personality disorder with and without co-occurring attention-deficit/hyperactivity disorder: an exploratory study. J Nerv Ment Dis. 2013;201(2):116-123. doi:10.1097/NMD.0b013e31827f6462

47. Mowinckel AM, Pedersen ML, Eilertsen E, Biele G. A meta-analysis of decision-making and attention in adults with ADHD. J Atten Disord. 2015;19(5):355-367. doi:10.1177/1087054714558872

48. Sebastian A, Jung P, Krause-Utz A, Lieb K, Schmahl C, Tüscher O. Frontal dysfunctions of impulse control - a systematic review in borderline personality disorder and attention-deficit/hyperactivity disorder. Front Hum Neurosci. 2014;8:698. doi:10.3389/fnhum.2014.00698

49. Xenaki L-A, Pehlivanidis A. Clinical, neuropsychological and structural convergences and divergences between attention deficit/ hyperactivity disorder and borderline personality disorder: a systematic review. Personal Individ Differ. 2015;86:438-449. doi:10.1016/j.paid.2015.06.049
50. Lawrence KA, Allen JS, Chanen AM. Impulsivity in borderline personality disorder: reward-based decision-making and its relationship to emotional distress. J Personal Disord. 2010;24 (6):786-799. doi:10.1521/pedi.2010.24.6.785

51. Coffey SF, Schumacher JA, Baschnagel JS, Hawk LW, Holloman G. Impulsivity and risk-taking in borderline personality disorder with and without substance use disorders. Personal Disord. 2011;2 (2):128-141. doi:10.1037/a0020574

52. Leyton M, Okazawa H, Diksic M, et al. Brain regional alpha-[11C] methyl-L-tryptophan trapping in impulsive subjects with borderline personality disorder. Am J Psychiatry. 2001;158(5):775-782. doi:10.1176/appi.ajp.158.5.775

53. McCloskey MS, New AS, Siever LJ, et al. Evaluation of behavioral impulsivity and aggression tasks as endophenotypes for borderline personality disorder. J Psychiatr Res. 2009;43(12):1036-1048. doi:10.1016/j.jpsychires.2009.01.002

54. Barker V, Romaniuk L, Cardinal RN, Pope M, Nicol K, Hall J. Impulsivity in borderline personality disorder. Psychol Med. 2015;45(9):1955-1964. doi:10.1017/S0033291714003079

55. Jacob GA, Gutz L, Bader K, Lieb K, Tüscher O, Stahl C. Impulsivity in borderline personality disorder: impairment in selfreport measures, but not behavioral inhibition. Psychopathology. 2010;43(3):180-188. doi:10.1159/000304174

56. van Dijk F, Schellekens A, van den Broek P, Kan C, Verkes R-J, Buitelaar J. Do cognitive measures of response inhibition differentiate between attention deficit/hyperactivity disorder and borderline personality disorder? Psychiatry Res. 2014;215(3):733-739. doi:10.1016/j.psychres.2013.12.034

57. Cackowski S, Reitz A-C, Ende G, et al. Impact of stress on different components of impulsivity in borderline personality disorder. Psychol Med. 2014;44(15):3329-3340. doi:10.1017/ S0033291714000427

58. Sebastian A, Jacob G, Lieb K, Tüscher O. Impulsivity in borderline personality disorder: a matter of disturbed impulse control or a facet of emotional dysregulation? Curr Psychiatry Rep. 2013;15 (2):339.

59. Santangelo P, Bohus M, Ebner-Priemer UW. Ecological momentary assessment in borderline personality disorder: a review of recent findings and methodological challenges. $J$ Personal Disord. 2014;28(4):555-576. doi:10.1521/pedi_2012_26_067

60. Rüfenacht E, Euler S, Prada P, et al. Emotion dysregulation in adults suffering from attention deficit hyperactivity disorder (ADHD), a comparison with borderline personality disorder (BPD). Borderline Personal Disord Emot Dysregulation. 2019;6:11. doi:10.1186/s40479-019-0108-1

61. Mörstedt B, Corbisiero S, Bitto H, Stieglitz R-D. Emotional symptoms and their contribution to functional impairment in adults with attention-deficit/hyperactivity disorder. Atten Deficit Hyperact Disord. 2016;8(1):21-33. doi:10.1007/s12402-015-0181-2

62. Skirrow C, Asherson P. Emotional lability, comorbidity and impairment in adults with attention-deficit hyperactivity disorder. $J$ Affect Disord. 2013;147(1):80-86. doi:10.1016/j.jad.2012.10.011

63. Vidal R, Valero S, Nogueira M, et al. Emotional lability: the discriminative value in the diagnosis of attention deficit/hyperactivity disorder in adults. Compr Psychiatry. 2014;55(7):1712-1719. doi:10.1016/j.comppsych.2014.07.001

64. Skirrow C, Ebner-Priemer U, Reinhard I, Malliaris Y, Kuntsi J, Asherson P. Everyday emotional experience of adults with attention deficit hyperactivity disorder: evidence for reactive and endogenous emotional lability. Psychol Med. 2014;44(16):3571-3583. doi:10.1017/S0033291714001032

65. Cavelti M, Corbisiero S, Bitto H, et al. A comparison of selfreported emotional regulation skills in adults with attention-deficit/hyperactivity disorder and borderline personality disorder. $J$ Atten Disord. 2017:1087054717698814. doi:10.1177/108705471 7698814 
66. Cackowski S, Krause-Utz A, Van Eijk J, et al. Anger and aggression in borderline personality disorder and attention deficit hyperactivity disorder - does stress matter? Borderline Personal Disord Emot Dysregulation. 2017;4:6. doi:10.1186/s40479-017-0057-5

67. Gratz KL, Roemer L. Multidimensional assessment of emotion regulation and dysregulation: development, factor structure, and initial validation of the difficulties in emotion regulation scale. $J$ Psychopathol Behav Assess. 2004;26(1):41-54. doi:10.1023/B: JOBA.0000007455.08539.94

68. Hirsch O, Chavanon M, Riechmann E, Christiansen H. Emotional dysregulation is a primary symptom in adult Attention-Deficit/ Hyperactivity Disorder (ADHD). J Affect Disord. 2018;232:4147. doi:10.1016/j.jad.2018.02.007

69. Roberts BA, Martel MM, Nigg JT. Are there executive dysfunction subtypes within ADHD? J Atten Disord. 2017;21(4):284-293. doi:10.1177/1087054713510349

70. Hirsch O, Chavanon ML, Christiansen H. Emotional dysregulation subgroups in patients with adult Attention-Deficit/Hyperactivity Disorder (ADHD): a cluster analytic approach. Sci Rep. 2019;9. doi:10.1038/s41598-019-42018-y

71. Moukhtarian TR, Mintah RS, Moran P, Asherson P. Emotion dysregulation in attention-deficit/hyperactivity disorder and borderline personality disorder. Borderline Personal Disord Emot Dysregulation. 2018;5:9. doi:10.1186/s40479-018-0086-8

72. Posner J, Kass E, Hulvershorn L. Using stimulants to treat ADHDrelated emotional lability. Curr Psychiatry Rep. 2014;16(10):478 doi:10.1007/s11920-014-0478-4

73. van Zutphen L, Siep N, Jacob GA, Goebel R, Arntz A. Emotional sensitivity, emotion regulation and impulsivity in borderline personality disorder: a critical review of fMRI studies. Neurosci Biobehav Rev. 2015;51:64-76. doi:10.1016/j.neubiorev.2015.01.001

74. Petrovic P, Castellanos FX. Top-down dysregulation-from ADHD to emotional instability. Front Behav Neurosci. 2016;10. doi:10.3 389/fnbeh.2016.00070

75. IsHak WW, Elbau I, Ismail A, et al. Quality of life in borderline personality disorder. Harv Rev Psychiatry. 2013;21(3):138-150. doi:10.1097/HRP.0b013e3182937116

76. Agarwal R, Goldenberg M, Perry R, Ishak WW. The quality of life of adults with attention deficit hyperactivity disorder. Innov Clin Neurosci. 2012;9(5-6):10-21.

77. Euler S, Nolte T, Constantinou M, et al. Interpersonal problems in borderline personality disorder: associations with mentalizing, emotion regulation, and impulsiveness. $J$ Personal Disord. 2019:1-17. doi:10.1521/pedi_2019_33_427

78. Uekermann J, Kraemer M, Abdel-Hamid M, et al. Social cognition in attention-deficit hyperactivity disorder (ADHD). Neurosci Biobehav Rev. 2010;34(5):734-743. doi:10.1016/j.neubiorev.2009. 10.009

79. Herr NR, Rosenthal MZ, Geiger PJ, Erikson K. Difficulties with emotion regulation mediate the relationship between borderline personality disorder symptom severity and interpersonal problems. Personal Ment Health. 2013;7(3):191-202. doi:10.1002/pmh.1204

80. Perroud N, Badoud D, Weibel S, et al. Mentalization in adults with attention deficit hyperactivity disorder: comparison with controls and patients with borderline personality disorder. Psychiatry Res. 2017;256:334-341. doi:10.1016/j.psychres.2017.06.087

81. Winsper C. The aetiology of borderline personality disorder (BPD): contemporary theories and putative mechanisms. Curr Opin Psychol. 2018;21:105-110. doi:10.1016/j.copsyc.2017.10.005

82. Fossati A, Madeddu F, Maffei C. Borderline personality disorder and childhood sexual abuse: a meta-analytic study. J Personal Disord. 1999;13(3):268-280.

83. Paris $\mathrm{J}$. The treatment of borderline personality disorder: implications of research on diagnosis, etiology, and outcome. Annu Rev Clin Psychol. 2009;5(1):277-290. doi:10.1146/annurev.clinpsy.03 12408.153457
84. Rucklidge JJ, Brown DL, Crawford S, Kaplan BJ. Retrospective reports of childhood trauma in adults with ADHD. J Atten Disord. 2006;9(4):631-641. doi:10.1177/1087054705283892

85. Distel MA, Middeldorp CM, Trull TJ, Derom CA, Willemsen G, Boomsma DI. Life events and borderline personality features: the influence of gene-environment interaction and gene-environment correlation. Psychol Med. 2011;41(4):849-860. doi:10.1017/ S0033291710001297

86. Distel MA, Carlier A, Middeldorp CM, Derom CA, Lubke GH, Boomsma DI. Borderline personality traits and adult attentiondeficit hyperactivity disorder symptoms: a genetic analysis of comorbidity. Am J Med Genet B Neuropsychiatr Genet. 2011;156 (7):817-825. doi:10.1002/ajmg.b.31226

87. Brikell I, Kuja-Halkola R, Larsson H. Heritability of attentiondeficit hyperactivity disorder in adults. Am J Med Genet Part B Neuropsychiatr Genet Off Publ Int Soc Psychiatr Genet. 2015;168 (6):406-413. doi:10.1002/ajmg.b.32335

88. Amad A, Ramoz N, Thomas P, Jardri R, Gorwood P. Genetics of borderline personality disorder: systematic review and proposal of an integrative model. Neurosci Biobehav Rev. 2014;40:6-19. doi:10.1016/j.neubiorev.2014.01.003

89. Newton-Howes G, Clark LA, Chanen A. Personality disorder across the life course. Lancet Lond Engl. 2015;385(9969):727734. doi:10.1016/S0140-6736(14)61283-6

90. Kuja-Halkola R, Juto KL, Skoglund C, et al. Do borderline personality disorder and attention-deficit/hyperactivity disorder co-aggregate in families? A population-based study of 2 million Swedes. Mol Psychiatry. 2018:1. doi:10.1038/s41380-018-0248-5

91. Mistry S, Escott-Price V, Florio AD, Smith DJ, Zammit S. Genetic risk for bipolar disorder and psychopathology from childhood to early adulthood. J Affect Disord. 2019;246:633-639. doi:10.1016/j. jad.2018.12.091

92. Wertz J, Caspi A, Ambler A, et al. Borderline symptoms at age 12 signal risk for poor outcomes during the transition to adulthood: findings from a genetically sensitive longitudinal cohort study. $J$ Am Acad Child Adolesc Psychiatry. 2019. doi:10.1016/j. jaac.2019.07.005

93. Zanarini MC, Frankenburg FR, Hennen J, Reich DB, Silk KR. Prediction of the 10-year course of borderline personality disorder. Am J Psychiatry. 2006;163(5):827-832. doi:10.1176/ajp.2006. 163.5 .827

94. Gunderson JG, Stout RL, McGlashan TH, et al. Ten-year course of borderline personality disorder. Arch Gen Psychiatry. 2011;68 (8):827-837. doi:10.1001/archgenpsychiatry.2011.37

95. Morgan TA, Chelminski I, Young D, Dalrymple K, Zimmerman M. Differences between older and younger adults with borderline personality disorder on clinical presentation and impairment. $J$ Psychiatr Res. 2013;47(10):1507-1513. doi:10.1016/j.jpsychires. 2013.06.009

96. Biederman J, Petty CR, Evans M, Small J, Faraone SV. How persistent is ADHD? A controlled 10-year follow-up study of boys with ADHD. Psychiatry Res. 2010;177(3):299-304. doi:10.1016/j.psychres.2009. 12.010

97. Moffitt TE, Houts R, Asherson P, et al. Is adult ADHD a childhoodonset neurodevelopmental disorder? Evidence from a four-decade longitudinal cohort study. Am J Psychiatry. 2015;172(10):967-977. doi:10.1176/appi.ajp.2015.14101266

98. Caye A, Rocha TB-M, Anselmi L, et al. Attention-deficit/hyperactivity disorder trajectories from childhood to young adulthood: evidence from a birth cohort supporting a late-onset syndrome. JAMA Psychiatry. 2016;73(7):705-712. doi:10.1001/jamapsychiatry.2016.0383

99. Agnew-Blais JC, Polanczyk GV, Danese A, Wertz J, Moffitt TE, Arseneault L. Evaluation of the persistence, remission, and emergence of attention-deficit/hyperactivity disorder in young adulthood. JAMA Psychiatry. 2016;73(7):713-720. doi:10.1001/jamapsychiatry. 2016.0465 
100. Castellanos FX. Is adult-onset ADHD a distinct entity? $A m J$ Psychiatry. 2015;172(10):929-931. doi:10.1176/appi.ajp.2015.15070 988

101. Asherson P, Agnew-Blais J. Annual research review: does lateonset attention-deficit/hyperactivity disorder exist? J Child Psychol Psychiatry. 2019;60(4):333-352. doi:10.1111/jcpp.13020

102. van Dijk F, Lappenschaar M, Kan C, Verkes R-J, Buitelaar J. Lifespan attention deficit/hyperactivity disorder and borderline personality disorder symptoms in female patients: a latent class approach. Psychiatry Res. 2011;190(2):327-334. doi:10.1016/j.psychres.2011.06.023

103. Lynn DE, Lubke G, Yang M, et al. Temperament and character profiles and the dopamine D4 receptor gene in ADHD. Am J Psychiatry. 2005;162(5):906-913. doi:10.1176/appi.ajp.162.5.906

104. Anckarsäter H, Stahlberg O, Larson T, et al. The impact of ADHD and autism spectrum disorders on temperament, character, and personality development. Am J Psychiatry. 2006;163(7):12391244. doi:10.1176/appi.ajp.163.7.1239

105. Fossati A, Donati D, Donini M, Novella L, Bagnato M, Maffei C. Temperament, character, and attachment patterns in borderline personality disorder. J Personal Disord. 2001;15(5):390-402. doi:10. 1521/pedi.15.5.390.19197

106. Barnow S, Herpertz SC, Spitzer C, et al. Temperament and character in patients with borderline personality disorder taking gender and comorbidity into account. Psychopathology. 2007;40(6):369378. doi:10.1159/000106467

107. Pinzone V, De Rossi P, Trabucchi G, Lester D, Girardi P, Pompili M. Temperament correlates in adult ADHD: a systematic review. $J$ Affect Disord. 2019;252:394-403. doi:10.1016/j.jad.2019.04.006

108. Cloninger CR, Svrakic DM, Przybeck TR. A psychobiological model of temperament and character. Arch Gen Psychiatry. 1993;50 (12):975-990. doi:10.1001/archpsyc.1993.01820240059008

109. Akiskal HS, Mendlowicz MV, Jean-Louis G, et al. TEMPS-A: validation of a short version of a self-rated instrument designed to measure variations in temperament. J Affect Disord. 2005;85(1-2):45-52. doi:10.1016/j.jad.2003.10.012

110. Perroud N, Cordera P, Zimmermann J, et al. Comorbidity between attention deficit hyperactivity disorder (ADHD) and bipolar disorder in a specialized mood disorders outpatient clinic. J Affect Disord. 2014;168:161-166. doi:10.1016/j.jad.2014.06.053

111. Eich D, Gamma A, Malti T, et al. Temperamental differences between bipolar disorder, borderline personality disorder, and attention deficit/hyperactivity disorder: some implications for their diagnostic validity. J Affect Disord. 2014;169:101-104. doi:10.1016/j. jad.2014.05.028

112. Carlotta D, Borroni S, Maffei C, Fossati A. On the relationship between retrospective childhood ADHD symptoms and adult BPD features: the mediating role of action-oriented personality traits. Compr Psychiatry. 2013;54(7):943-952. doi:10.1016/j.comppsych.2013.03.025

113. Battle CL, Shea MT, Johnson DM, et al. Childhood maltreatment associated with adult personality disorders: findings from the Collaborative Longitudinal Personality Disorders Study. J Personal Disord. 2004;18(2):193-211. doi:10.1521/pedi.18.2.193.32777

114. van Dijke A, Ford JD, van der Hart O, van Son M, van der Heijden P, Bühring M. Affect dysregulation in borderline personality disorder and somatoform disorder: differentiating under- and over-regulation. $J$ Personal Disord. 2010;24(3):296-311. doi:10.1521/pedi.2010.24.3.296

115. Björkenstam E, Ekselius L, Burström B, Kosidou K, Björkenstam C. Association between childhood adversity and a diagnosis of personality disorder in young adulthood: a cohort study of 107,287 individuals in Stockholm County. Eur J Epidemiol. 2017;32(8):721-731. doi:10.1007/s10654-017-0264-9

116. Björkenstam E, Björkenstam C, Jablonska B, Kosidou K. Cumulative exposure to childhood adversity, and treated attention deficit/hyperactivity disorder: a cohort study of 543650 adolescents and young adults in Sweden. Psychol Med. 2018;48(3):498-507. doi:10.1017/S0033291717001933
117. Ferrer M, Andión Ó, Calvo N, et al. Differences in the association between childhood trauma history and borderline personality disorder or attention deficit/hyperactivity disorder diagnoses in adulthood. Eur Arch Psychiatry Clin Neurosci. 2017;267(6):541-549. doi:10.1007/s00406-016-0733-2

118. Bernstein DP, Stein JA, Newcomb MD, et al. Development and validation of a brief screening version of the childhood trauma questionnaire. Child Abuse Negl. 2003;27(2):169-190. doi:10.1 016/S0145-2134(02)00541-0

119. Fossati A, Gratz KL, Borroni S, Maffei C, Somma A, Carlotta D. The relationship between childhood history of ADHD symptoms and DSM-IV borderline personality disorder features among personality disordered outpatients: the moderating role of gender and the mediating roles of emotion dysregulation and impulsivity. Compr Psychiatry. 2015;56:121-127. doi:10.1016/j.comppsych. 2014.09.023

120. ROGOSCH FA, CICCHETTI D. Child maltreatment, attention networks, and potential precursors to borderline personality disorder. Dev Psychopathol. 2005;17(4):1071-1089. doi:10.1017/S09545794 05050509

121. Minzenberg MJ, Poole JH, Vinogradov S. A neurocognitive model of borderline personality disorder: effects of childhood sexual abuse and relationship to adult social attachment disturbance. Dev Psychopathol. 2008;20(1):341-368. doi:10.1017/S09545794080 00163

122. Kolb B, Mychasiuk R, Muhammad A, Li Y, Frost DO, Gibb R. Experience and the developing prefrontal cortex. Proc Natl Acad Sci U S A. 2012;109(Suppl 2):17186-17193. doi:10.1073/pnas. 1121251109

123. Angst J, Gamma A, Rössler W, Ajdacic V, Klein DN. Childhood adversity and chronicity of mood disorders. Eur Arch Psychiatry Clin Neurosci. 2011;261(1):21-27. doi:10.1007/s00406-010-0120-3

124. Binder EB. Understanding gene $\times$ early adversity interactions: possibilities for insight in the biology of psychiatric disorders. Eur Arch Psychiatry Clin Neurosci. 2017;267(3):183-185. doi:10. 1007/s00406-017-0775-0

125. Perroud N, Zewdie S, Stenz L, et al. Methylation of serotonin receptor $3 \mathrm{a}$ in Adhd, borderline personality, and bipolar disorders: link with severity of the disorders and childhood maltreatment. Depress Anxiety. 2016;33(1):45-55. doi:10.1002/da.22 406

126. Perroud N, Paoloni-Giacobino A, Prada P, et al. Increased methylation of glucocorticoid receptor gene $(\mathrm{NR} 3 \mathrm{C} 1)$ in adults with a history of childhood maltreatment: a link with the severity and type of trauma. Transl Psychiatry. 2011;1:e59. doi:10.1038/ tp. 2011.60

127. National Collaborating Centre for Mental Health (UK). Borderline Personality Disorder: Treatment and Management. Leicester (UK): British Psychological Society; 2009. Available from: http://www.ncbi.nlm.nih.gov/books/NBK55403/. Accessed September 15, 2019.

128. Golubchik P, Sever J, Zalsman G, Weizman A. Methylphenidate in the treatment of female adolescents with cooccurrence of attention deficit/hyperactivity disorder and borderline personality disorder: a preliminary open-label trial. Int Clin Psychopharmacol. 2008;23 (4):228. doi:10.1097/YIC.0b013e3282f94ae2

129. Prada P, Nicastro R, Zimmermann J, Hasler R, Aubry J-M, Perroud $N$. Addition of methylphenidate to intensive dialectical behaviour therapy for patients suffering from comorbid borderline personality disorder and ADHD: a naturalistic study. ADHD Atten Deficit Hyperact Disord. 2015;7(3):199-209. doi:10.1007/s12402-0150165-2

130. Cole P, Weibel S, Nicastro R, et al. CBT/DBT skills training for adults with attention deficit hyperactivity disorder (ADHD). Psychiatr Danub. 2016;28(Suppl-1):103-107. 
131. Fleming AP, McMahon RJ, Moran LR, Peterson AP, Dreessen A. Pilot randomized controlled trial of dialectical behavior therapy group skills training for ADHD among college students. J Atten Disord. 2015;19(3):260-271. doi:10.1177/10870 54714535951
132. Philipsen A, Graf E, Tebartz van Elst L, et al. Evaluation of the efficacy and effectiveness of a structured disorder tailored psychotherapy in ADHD in adults: study protocol of a randomized controlled multicentre trial. Atten Deficit Hyperact Disord. 2010;2 (4):203-212. doi:10.1007/s12402-010-0046-7

\section{Publish your work in this journal}

Neuropsychiatric Disease and Treatment is an international, peerreviewed journal of clinical therapeutics and pharmacology focusing on concise rapid reporting of clinical or pre-clinical studies on a range of neuropsychiatric and neurological disorders. This journal is indexed on PubMed Central, the 'PsycINFO' database and CAS, and is the official journal of The International Neuropsychiatric Association (INA). The manuscript management system is completely online and includes a very quick and fair peer-review system, which is all easy to use. Visit http://www.dovepress.com/testimonials.php to read real quotes from published authors.

Submit your manuscript here: https://www.dovepress.com/neuropsychiatric-disease-and-treatment-journal 